\title{
Phase II study of two dose schedules of C.E.R.A. (Continuous Erythropoietin Receptor Activator) in anemic patients with advanced non-small cell lung cancer (NSCLC) receiving chemotherapy
}

\author{
Vera Hirsh*1, John Glaspy², Paul Mainwaring3, Christian Manegold4, \\ Rodryg Ramlau ${ }^{5}$ and Joseph E Eid ${ }^{6}$
}

\begin{abstract}
Address: ${ }^{1}$ Royal Victoria Hospital, McGill University Health Center, Montreal, Quebec, Canada, ${ }^{2}$ Division of Hematology-Oncology, UCLA School of Medicine, Los Angeles, CA, USA, ${ }^{3}$ Medical Oncology, Mater Adult Hospital, South Brisbane, Australia, ${ }^{4}$ Heidelberg University Medical Center, Mannheim, Germany, ${ }^{5}$ Regional Center of Lung Diseases, Poznań, Poland and ${ }^{6}$ Hoffmann-La Roche Inc., Nutley, NJ, USA

Email: Vera Hirsh* - vera.hirsh@muhc.mcgill.ca; John Glaspy - jglaspy@mednet.ucla.edu; Paul Mainwaring - paul.mainwaring@mater.org.au; Christian Manegold - prof.manegold@t-online.de; Rodryg Ramlau - rramlau@wcchpig.pl; Joseph E Eid - joseph.eid@roche.com

* Corresponding author
\end{abstract}

\section{Published: 6 March 2007}

Trials 2007, 8:8 doi:10.1186/1745-62/5-8-8

This article is available from: http://www.trialsjournal.com/content/8/I/8

(C) 2007 Hirsh et al; licensee BioMed Central Ltd.

This is an Open Access article distributed under the terms of the Creative Commons Attribution License (http://creativecommons.org/licenses/by/2.0), which permits unrestricted use, distribution, and reproduction in any medium, provided the original work is properly cited.
Received: 5 September 2006

Accepted: 6 March 2007

\begin{abstract}
Background: C.E.R.A. (Continuous Erythropoietin Receptor Activator) is an innovative agent with unique erythropoietin receptor activity and prolonged half-life. This study evaluated C.E.R.A. once weekly (QW) or once every 3 weeks (Q3W) in patients with anemia and advanced non-small cell lung cancer (NSCLC) receiving chemotherapy.

Methods: In this Phase II, randomized, open-label, multicenter, dose-finding study, patients $(n=218)$ with Stage IIIB or IV NSCLC and hemoglobin $(\mathrm{Hb}) \leq \mathrm{II}$ g/dL were randomized to one of six treatment groups of C.E.R.A. administered subcutaneously for 12 weeks: 0.7 , I.4, or $2.1 \mu \mathrm{g} / \mathrm{kg}$ QW or 2.1 , 4.2 , or $6.3 \mu \mathrm{g} / \mathrm{kg}$ Q3W. Primary endpoint was average $\mathrm{Hb}$ level between baseline and end of initial treatment (defined as last $\mathrm{Hb}$ measurement before dose reduction or transfusion, or the value at week 13). Hematopoietic response ( $\mathrm{Hb}$ increase $\geq 2 \mathrm{~g} / \mathrm{dL}$ or achievement of $\mathrm{Hb} \geq 12 \mathrm{~g} / \mathrm{dL}$ with no blood transfusion in the previous 28 days determined in two consecutive measurements within a 10-day interval) was also measured.

Results: Dose-dependent $\mathrm{Hb}$ increases were observed, although the magnitude of increase was moderate. Hematopoietic response rate was also dose dependent, achieved by $51 \%$ and $62 \%$ of patients in the 4.2 and $6.3 \mu \mathrm{g} / \mathrm{kg}$ Q3W groups, and $63 \%$ of the $2.1 \mu \mathrm{g} / \mathrm{kg}$ QW group. In the Q3W group, the proportion of early responders (defined as $\geq \mathrm{I} / \mathrm{g} / \mathrm{dL}$ increase in $\mathrm{Hb}$ from baseline during the first 22 days) increased with increasing C.E.R.A. dose, reaching $41 \%$ with the highest dose. In the $6.3 \mu \mathrm{g} / \mathrm{kg}$ Q3W group, $15 \%$ of patients received blood transfusion. There was an inclination for higher mean $\mathrm{Hb}$ increases and lower transfusion use in the Q3W groups than in the QW groups. C.E.R.A. was generally well tolerated.

Conclusion: C.E.R.A. administered QW or Q3W showed clinical activity and safety in patients with NSCLC. There were dose-dependent increases in $\mathrm{Hb}$ responses. C.E.R.A. appeared to be more effective when the same dose over time was given Q3W than QW, with a suggestion that C.E.R.A. 6.3 $\mu$ g/kg Q3W provided best efficacy in this study. However, further dose-finding studies using higher doses are required to determine the optimal C.E.R.A. dose regimen in cancer patients receiving chemotherapy.
\end{abstract}




\section{Background}

Non-small cell lung cancer (NSCLC) is one of the most common tumors diagnosed in Western countries. The predicted incidence of lung cancer in the US was 173,000 new cases in 2005 [1], of which most (over 80\%) will have a diagnosis of NSCLC. The majority of patients with Stage IIIB (pleural effusion) or Stage IV NSCLC require chemotherapy as part of their management program, which is often toxic; current first-line standards of care for Stage III-IV NSCLC use platinum compounds (such as carboplatin or cisplatin) combined with gemcitabine, vinorelbine, or taxanes, usually administered in 3-week cycles [2-5].

The prevalence of anemia (defined as hemoglobin $[\mathrm{Hb}]<$ $11 \mathrm{~g} / \mathrm{dL}$ ) in patients with lung cancer ranges from $50 \%$ to $60 \%$, and blood transfusions are common, with $30 \%$ to $40 \%$ of patients requiring this treatment $[6,7]$. The cause of cancer-related anemia is often multifactorial. It is associated with the excessive release of cytokines such as interleukin-1, tumor necrosis factor, and interferons, which interfere with the production of endogenous erythropoietin and inhibit erythroid bone marrow production $[8,9]$. The anemia is also exacerbated by the use of myelosuppressive combination chemotherapy, particularly with platinum compounds [5].

Anemia has a major impact on the quality of life (QoL) of patients with cancer, its symptoms including fatigue, dizziness, headache, and shortness of breath [10-12]. In patients with lung cancer, these symptoms are often enhanced by diminished pulmonary function and the frequent presence of comorbidities [11]. Anemia has also been shown to be associated with a diminished response to chemotherapy and a decreased survival in patients with NSCLC [13-15]. Blood transfusions provide effective acute relief of anemia, but their effects are short-lived and they are associated with significant risks such as transfusion reactions and transmission of infection $[16,17]$.

Treatment of chemotherapy-associated anemia with the erythropoiesis-stimulating agents (ESAs), epoetin alfa, epoetin beta, and darbepoetin alfa, has been shown to increase Hb levels, thereby reducing the need for transfusions and improving QoL [18-22]. In anemic patients with cancer, ESAs were initially administered three-times weekly, a schedule that had already proved effective in patients with renal anemia. Recently, there have been moves towards once weekly (QW) administration with all ESAs $[20,23,24]$. Darbepoetin alfa has also been licensed recently for once every 3 weeks (Q3W) use in anemic patients receiving chemotherapy for cancer. Given the increased convenience of once per cycle dosing, it is important that new agents being developed for the treat- ment of chemotherapy-induced anemia are studied at intervals of Q3W.

Continuous Erythropoietin Receptor Activator (C.E.R.A.) is an innovative agent with unique receptor activity and a prolonged half-life. It is a chemically synthesized C.E.R.A. that differs from erythropoietin through the integration of amide bonds between amino groups and methoxy polyethylene glycolsuccinimidyl butanoic acid [25,26]. C.E.R.A. is currently in development to provide correction of anemia and stable control of Hb levels at extended administration intervals in patients with cancer $[26,27]$.

Studies in healthy volunteers demonstrated that C.E.R.A. had lower systemic clearance and an increased elimination half-life $\left(\mathrm{t}_{1 / 2}\right)$ compared with other ESAs, and superior potency in vivo with respect to the magnitude and duration of response $[28,29]$. Further healthy volunteer studies demonstrated rapid, dose-dependent increases in reticulocytes following either intravenous or subcutaneous (SC) administration of C.E.R.A. [30]. An exploratory Phase I-II dose-escalation study in anemic patients with multiple myeloma receiving myelosuppressive chemotherapy (selected as a more responsive population to ESA treatment based on their baseline ratio of observed/predicted erythropoietin levels) confirmed the long half-life of C.E.R.A. (median 6.3-9.7 days) [27]. Also, a dosedependent increase in $\mathrm{Hb}$ response was observed with C.E.R.A. doses up to $8 \mu \mathrm{g} / \mathrm{kg}$ when administered Q3W by SC injection. An $\mathrm{Hb}$ increase of $\geq 2 \mathrm{~g} / \mathrm{dL}$ in the first 6 weeks was achieved in $50.0 \%-62.5 \%$ of patients treated with C.E.R.A. 3.5-8.0 $\mu \mathrm{g} / \mathrm{kg}$ Q3W.

This multicenter, open-label, randomized study was designed to evaluate the efficacy, safety, and pharmacokinetic profile of C.E.R.A. administered SC QW or Q3W to patients with anemia and advanced (Stage IIIB or IV) NSCLC receiving chemotherapy. A further aim was to determine the optimum C.E.R.A. dose. The dose range chosen was based on that used in the previous study in multiple myeloma patients [27].

\section{Methods \\ Patients}

Patients eligible for study inclusion were adults (aged $\geq 18$ years) with Stage IIIB or IV NSCLC and a Hb level of $\leq 11$ $\mathrm{g} / \mathrm{dL}$ at screening. Patients were receiving first or second line chemotherapy at screening, which continued for at least 9 weeks during the study. Additionally, patients had an Eastern Cooperative Oncology Group (ECOG) performance status grade of 0-2 (first-line chemotherapy) or $0-1$ (second-line chemotherapy) and a life expectancy of $>6$ months. 
Patients were excluded from the study if they had received a red blood cell transfusion or radiation therapy in the 4 weeks before the first planned dose of study medication, or had any active second malignancy within the previous 5 years, excluding basal cell carcinoma and squamous cell carcinoma of the skin, or cervical carcinoma in situ. Other exclusion criteria included: brain metastasis; clinically significant hypertension; acute or chronic bleeding requiring treatment within 3 months of the study start; functional iron deficiency (transferrin saturation $<20 \%$ and serum ferritin < $100 \mathrm{ng} / \mathrm{mL}$ ); grade $3 / 4$ thrombocytopenia (platelet count $<50 \times 10^{9} / \mathrm{L}$ ) or thrombocytosis (platelet count $\left.>500 \times 10^{9} / \mathrm{L}\right)$; creatinine $>2.5 \mathrm{mg} / \mathrm{dL}$; C-reactive protein $(\mathrm{CRP})>50 \mathrm{mg} / \mathrm{L} ;$ known folic acid/B ${ }_{12}$ deficiency or hemolysis; history of seizure, acute infection or inflammatory disease; pregnancy or lactation. Patients were also excluded if they had been treated with ESA therapy in the 8 weeks before study drug administration and were known to have resistance to ESA administration.

\section{Study design}

This was a Phase II, randomized, open-label, multicenter, dose-finding study where patients were planned to receive C.E.R.A. SC injections over a 12-week treatment period. The design and conduct of the study complied with the principles of good clinical practice, in accordance with the Declaration of Helsinki. The study was approved by local ethics committees and informed written consent was obtained from all patients before enrollment.

\section{C.E.R.A. administration and dose adjustment}

Eligible patients were randomized to one of six treatment groups in two dose schedules: C.E.R.A. $0.7,1.4$, or $2.1 \mu \mathrm{g} /$ kg QW or C.E.R.A. 2.1, 4.2, or $6.3 \mu \mathrm{g} / \mathrm{kg}$ Q3W. Patients received the first dose of study drug not more than 14 days after they were screened. The first dose of C.E.R.A. was given on day one of the cycle, before the administration of cyclic chemotherapy. Dose changes were made based upon the Hb levels on dosing day (within 24 hours). No dose increases of C.E.R.A. were allowed. If the $\mathrm{Hb}$ level increased by $>2 \mathrm{~g} / \mathrm{dL}$ within 2 weeks, or if the $\mathrm{Hb}$ was $>$ $12 \mathrm{~g} / \mathrm{dL}$ and $\leq 13 \mathrm{~g} / \mathrm{dL}$, the current dose was reduced by $50 \%$. Instructions were given to the investigators to reduce the dose only once during the study, when these criteria were met. Treatment was withheld if the Hb level was $>13$ $\mathrm{g} / \mathrm{dL}$ until a value of $\leq 12 \mathrm{~g} / \mathrm{dL}$ was achieved. Treatment was then resumed at $50 \%$ of the previous dose. If the $\mathrm{Hb}$ level was > $14 \mathrm{~g} / \mathrm{dL}$, patients were evaluated for appropriate clinical intervention (for example, phlebotomy or use of fluids if hydration was considered necessary).

\section{Assessments}

Hematology parameters, vital signs, and body weight were measured at screening and weekly thereafter. Blood samples for pharmacokinetic assessment and laboratory tests (including blood chemistry and iron parameters) were taken and assessed at baseline and at regular intervals thereafter. Electrocardiogram (ECG) readings and anti-C.E.R.A. antibodies were analyzed at weeks 4, 8, 13 (or end of the study), and at a follow-up visit 8 weeks after the last dose of C.E.R.A. Adverse events, iron supplementation, blood transfusions, and concomitant medications were documented throughout the course of the study.

\section{Endpoints \\ Efficacy}

The primary efficacy endpoint was the average Hb level between baseline and end of initial treatment, defined as the last $\mathrm{Hb}$ measurement before a dose reduction or transfusion, or the value at week 13, whichever came first. Secondary endpoints included the following parameters: the $\mathrm{Hb}$ response, which was defined as an increase in $\mathrm{Hb}$ of $\geq$ $2 \mathrm{~g} / \mathrm{dL}$ from baseline on two consecutive measurements within a 10-day interval at any time during the study, with no blood transfusion in the previous 28 days; the hematopoietic response, which was defined as a $\mathrm{Hb}$ response or achievement of $\mathrm{Hb} \geq 12 \mathrm{~g} / \mathrm{dL}$ at any time during the study, with no blood transfusion in the previous 28 days. Changes in $\mathrm{Hb}$, hematocrit, and reticulocyte counts were assessed over time, together with the requirement for any blood transfusions.

Two additional analyses not included in the study protocol were also performed. First, the average change in $\mathrm{Hb}$ level was assessed from baseline during week 5 to the end of study (week 13 or last assessment). In the event of blood transfusion, the last $\mathrm{Hb}$ value in the preceding 2 days was carried forward for the next 28 days. Second, responder categorization was performed as follows: 'early responders', defined as patients with $\mathrm{a} \geq 1 \mathrm{~g} / \mathrm{dL}$ increase in $\mathrm{Hb}$ from baseline during the first 22 days, with no concomitant blood transfusion during the study; 'additional responders', defined as patients who were not early responders but achieved the target therapeutic range of 11-13 g/dL during the study without blood transfusion; 'non-responders', defined as patients who did not qualify as 'early responders' or 'additional responders'.

\section{Pharmacokinetics}

Serum concentrations of C.E.R.A. were measured using an enzyme-linked immunosorbent assay (ELISA) with a limit of quantification of $150 \mathrm{pg} / \mathrm{mL}$ and used to determine the maximum serum concentration $\left(\mathrm{C}_{\max }\right)$ and time to maximum serum concentration $\left(\mathrm{T}_{\max }\right)$. The $\mathrm{t}_{1 / 2}$ was estimated for $\ln (2) / k$, where the rate constant of elimination $(k)$ was determined by linear regression on the logarithm of the serum concentration versus time data in the post-distribution phase. The area under the concentration-time curve (AUC) following C.E.R.A. administration, from pre-dose on day 22 until the last sampling time at which the con- 
centration was measurable (day 29 for the QW group and day 43 for the Q3W group), was estimated by the linear trapezoidal rule.

\section{Safety}

Safety endpoints included adverse events, clinical laboratory tests, vital signs, body weight, physical examination, and ECGs. The intensities of adverse events and laboratory values were graded according to the National Cancer Institute/National Institutes of Health Common Toxicity Criteria.

\section{Statistical analyses}

A sample size of 210 patients (35 per treatment group) was calculated to have $90 \%$ power in rejecting the overall F-test of no difference among the three treatment groups in each dose schedule group in the primary efficacy variable at the alpha level of 0.025 (2-sided). The $90 \%$ power and 0.025 significance level were chosen to address the multiple testing of the two-dosing schedule. This sample size included an anticipated dropout rate of $10 \%$.

The efficacy of study medications was primarily evaluated for the intent-to-treat (ITT) population, which included patients who were randomized and received at least one dose of study medication. A per-protocol (PP) analysis was also performed, which included patients who met the inclusion criteria, did not receive blood transfusions during the study, and had no major protocol violations that are known to affect response to ESAs, such as blood transfusions in the 4-week period before first planned dose of C.E.R.A., functional iron deficiency (serum ferritin $<100$ $\mathrm{ng} / \mathrm{mL}$ and transferrin saturation $<20 \%$ ), known hemolysis or acute infection or inflammatory disease (CRP $>50$ $\mathrm{mg} / \mathrm{L}$ ). Patients with blood transfusions during the study were not considered protocol violations, but they were excluded from the PP analysis to avoid the compounding effect of transfusions on efficacy variables, such as change in $\mathrm{Hb}$ levels. The safety population included all randomized patients who received at least one dose of study medication.

The primary efficacy variable was the average Hb level during the period from baseline until the end of initial treatment (defined as last observed value before a dose change or blood transfusion) and was based on AUC using linear trapezoidal rule). This AUC approach was chosen in consideration of the commonly observed large variability in $\mathrm{Hb}$ measurements, since the cumulative effects on $\mathrm{Hb}$ level are assessed rather than $\mathrm{Hb}$ changes at one or two time points, enabling robust evaluation of biological activity of the treatment based on the benefits over the entire course of therapy. Average Hb level from baseline to end of initial treatment was analyzed using an analysis of covariance (ANCOVA) model, with treatment group as a fixed factor and baseline $\mathrm{Hb}$ as a covariate. The average $\mathrm{Hb}$ change from baseline during week 5 until the end of study (week 13 or last available assessment) was also analyzed by ANCOVA, as for the primary efficacy variable. Cumulative response rates over time were estimated by Kaplan-Meier methods. All data, including $\mathrm{Hb}$ values for each assessment visit and pharmacokinetic parameters, were summarized using descriptive statistics.

\section{Results \\ Patient disposition}

A total of 218 patients with NSCLC were enrolled into the study from 61 centers in North America, Central America, Europe, Asia, and Australia. Of these, 109 were randomized to one of the QW doses of C.E.R.A.; 36 to the 0.7 $\mu \mathrm{g} / \mathrm{kg}$ group, 37 to the $1.4 \mu \mathrm{g} / \mathrm{kg}$ group, and 36 to the 2.1 $\mu \mathrm{g} / \mathrm{kg}$ group. The other 109 patients were randomized to Q3W doses: 37 to the $2.1 \mu \mathrm{g} / \mathrm{kg}$ group, 37 to the $4.2 \mu \mathrm{g} / \mathrm{kg}$ group, and 35 to the $6.3 \mu \mathrm{g} / \mathrm{kg}$ group. The flow of patients through the study is shown in Figure 1. One patient in the QW group $(2.1 \mu \mathrm{g} / \mathrm{kg}$ subgroup) and four patients in the Q3W group (three in the $2.1 \mu \mathrm{g} / \mathrm{kg}$ subgroup and one in the $6.3 \mu \mathrm{g} / \mathrm{kg}$ subgroup) did not receive any study drug after randomization and were not included in the ITT, PP, and safety analysis populations. The mean duration on study was similar across the six dose groups (74-81 days).

In the QW group, 18 patients were withdrawn from the study for the following reasons: adverse events (eight patients), death (six patients), refused treatment (three patients), and withdrawal at the discretion of the investigator (one patient). In the Q3W group, 24 patients were withdrawn for similar reasons: death (11 patients), adverse events (five patients), refused treatment or failed to return (seven patients), and a site error (one patient, who was started on third-line treatment [gefitinib] and the investigator thought the patient had to be withdrawn). Figure 1 gives the reasons for withdrawal by treatment group.

In the QW and Q3W groups, five and three further deaths, respectively, occurred after study completion. All the deaths were considered by the investigator to be unrelated to study medication. Overall, 44 and 36 patients in the QW and Q3W groups, respectively, were excluded from the PP population, the most common reason being the need for blood transfusion during treatment in $39(89 \%)$ and $28(78 \%)$ patients, respectively (Table 1$)$.

\section{Baseline characteristics}

The demographics and clinical characteristics at baseline were comparable among the $\mathrm{QW}$ and $\mathrm{Q} 3 \mathrm{~W}$ treatment groups (Table 2). The majority of patients had Stage IV NSCLC and had received chemotherapy before the start of the study. Approximately one-fifth to one-third of 


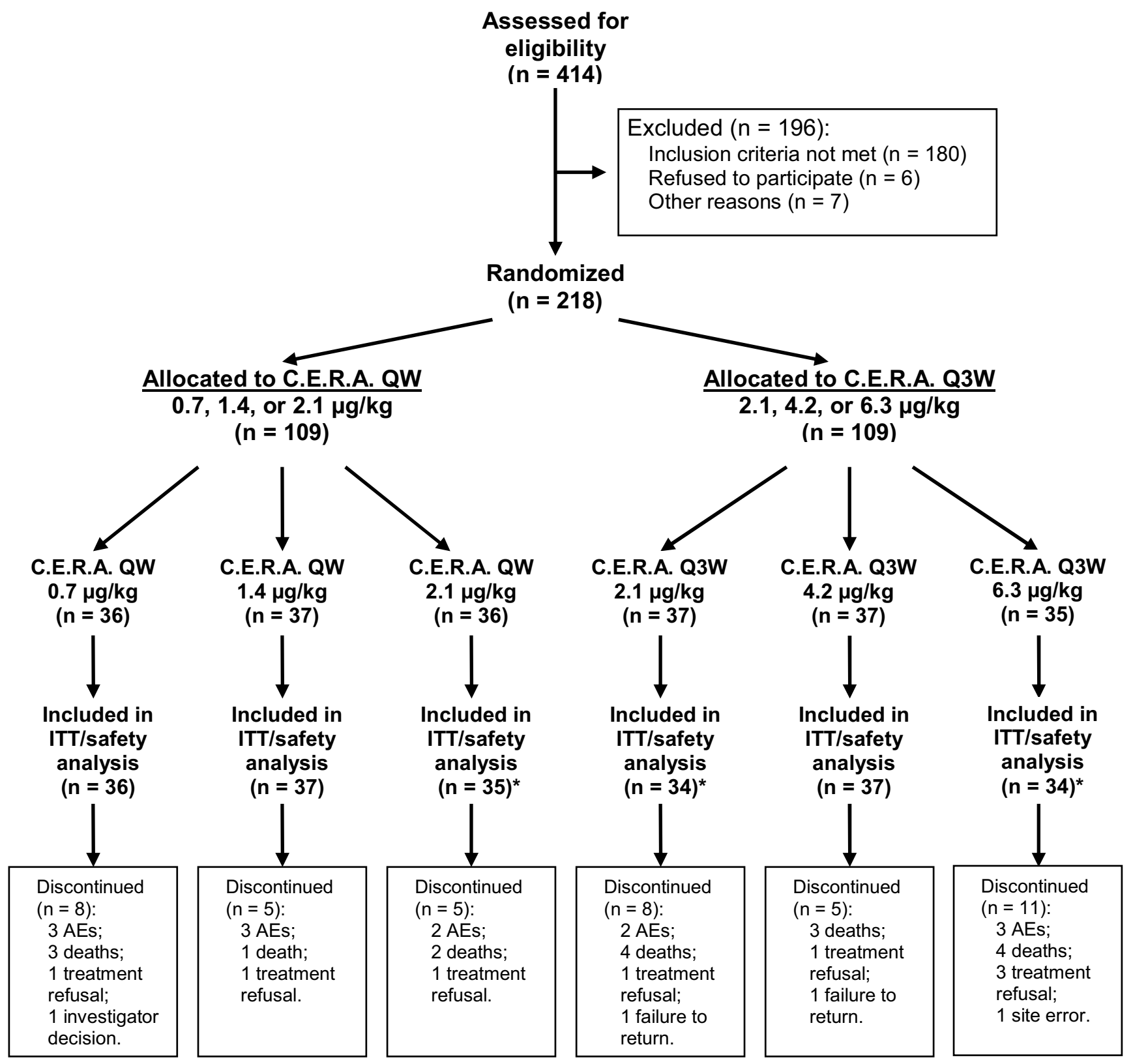

Figure I

Patient flowchart.

AEs: adverse events.

C.E.R.A.: Continuous Erythropoietin Receptor Activator.

ITT: intent to treat.

QW: once weekly.

Q3W: once ever 3 weeks.

*One patient in the C.E.R.A. 2.I $\mu \mathrm{g} / \mathrm{kg}$ QW group, three patients in the $2.1 \mu \mathrm{g} / \mathrm{kg}$ Q3W group and one patient in the $6.3 \mu g / \mathrm{kg}$ Q3W group were excluded from the ITT and safety analyses because they did not receive any study drug. 
Table I: Analysis populations and reasons for exclusion from the per-protocol population.

\begin{tabular}{|c|c|c|c|c|c|c|}
\hline & \multicolumn{3}{|c|}{ C.E.R.A. dose group ( $\mu$ g/kg QW) } & \multicolumn{3}{|c|}{ C.E.R.A. dose group ( $\mu$ g/kg Q3W) } \\
\hline & 0.7 & 1.4 & 2. 1 & 2. I & 4.2 & 6.3 \\
\hline Number of patients randomized & 36 & 37 & 36 & 37 & 37 & 35 \\
\hline Number of patients in ITT/safety population* & 36 & 37 & 35 & 34 & 37 & 34 \\
\hline Number of patients in PP population & 22 & 23 & 20 & 21 & 27 & 25 \\
\hline Number of randomized patients excluded from PP population & 14 & 14 & 16 & 16 & 10 & 10 \\
\hline \multicolumn{7}{|l|}{ Reasons for exclusion from PP population** } \\
\hline Blood transfusion during study period & 13 & 12 & 14 & 16 & 7 & 5 \\
\hline Acute infection/inflammatory disease (CRP > 50 mg/L) & 1 & 4 & 1 & 2 & 3 & 3 \\
\hline Received no study medication & 0 & 0 & I & 3 & 0 & I \\
\hline Blood transfusion during 4-week period before study entry & 0 & 0 & 0 & 3 & 0 & 0 \\
\hline Inclusion criteria not met & 0 & 0 & 0 & 0 & 0 & I \\
\hline
\end{tabular}

C.E.R.A.: Continuous Erythropoietin Receptor Activator.

CRP: C-reactive protein.

ITT: intent-to-treat.

PP: per-protocol.

QW: once weekly.

Q3W: once every 3 weeks.

*One patient in the C.E.R.A. $2.1 \mu \mathrm{g} / \mathrm{kg}$ QW group, three patients in the $2.1 \mu \mathrm{g} / \mathrm{kg}$ Q3W group and one patient in the $6.3 \mu \mathrm{g} / \mathrm{kg}$ Q3W group were

excluded from the ITT and safety analyses because they did not receive any study drug.

**Patients may have had more than one reason for being excluded from the PP population.

patients in each dose group had undergone surgery and/ or radiotherapy. The median $\mathrm{Hb}$ level at baseline was similar among treatment groups, ranging from $10.1 \mathrm{~g} / \mathrm{dL}$ to $10.6 \mathrm{~g} / \mathrm{dL}$ (Table 2).

All patients received chemotherapy during the study, which was most commonly platinum based (carboplatin and cisplatin; $83 \%, 59 \%$, and $71 \%$ in the $0.7,1.4$, and 2.1 $\mu \mathrm{g} / \mathrm{kg}$ QW groups; $91 \%, 68 \%$, and $65 \%$ in the $2.1,4.2$, and $6.3 \mu \mathrm{g} / \mathrm{kg} \mathrm{Q} 3 \mathrm{~W}$ groups, respectively). Other most common chemotherapies included gemcitabine hydrochloride (43\%-53\% in the QW group and $41 \%-53 \%$ in the Q3W group) and taxanes (28\%-46\% in the QW group and $30 \%-44 \%$ in the Q3W group).

Overall, 97 patients received iron therapy and of these most (87 patients [90\%]) received oral iron supplementation. The proportion of patients receiving intravenous iron supplementation was similar across all six C.E.R.A. groups. The percentage of patients receiving concomitant oral iron supplements was somewhat higher in patients who received C.E.R.A. Q3W (46\% to 53\%) than in patients treated QW (26\% to $36 \%$ ).

\section{Efficacy}

Except where stated, all efficacy analyses were conducted for the ITT population. For the primary endpoint, the mean $\mathrm{Hb}$ change from baseline during the initial treatment period was for the QW group: -0.36 (95\% confidence interval [CI]: -0.66 to -0.07$),-0.19$ (95\% CI: -0.48 to +0.10$)$, and $-0.06 \mathrm{~g} / \mathrm{dL}(95 \% \mathrm{CI}:-0.36$ to +0.24$)$ in the $0.7,1.4$, and $2.1 \mu \mathrm{g} / \mathrm{kg}$ groups, respectively. For the Q3W group, the mean $\mathrm{Hb}$ changes were -0.23 ( $95 \% \mathrm{CI}$ : -0.54 to
$+0.08),-0.07(95 \%$ CI: -0.37 to +0.23$)$, and $0.28 \mathrm{~g} / \mathrm{dL}$ (95\% CI: -0.03 to +0.59 ) in the $2.1,4.2$, and $6.3 \mu \mathrm{g} / \mathrm{kg}$ groups, respectively. Similar inclinations were observed in the PP population (mean increases $-0.21,-0.08,0.31 \mathrm{~g} / \mathrm{dL}$ for the QW dose groups and $0.07,0.23,0.42 \mathrm{~g} / \mathrm{dL}$ for the Q3W dose groups, respectively).

As $\mathrm{Hb}$ levels declined during the first few weeks of C.E.R.A. therapy in patients receiving concomitant chemotherapy, an additional analysis was performed to determine the average $\mathrm{Hb}$ changes from baseline during weeks 5 and 13 (or last assessment). Dose-dependent increases in $\mathrm{Hb}$ were observed in the QW and Q3W groups, with an increase of $0.66 \mathrm{~g} / \mathrm{dL}$ in the $6.3 \mu \mathrm{g} / \mathrm{kg}$ Q3W group (Table $3)$.

Hb response (defined as two consecutive, within 10-day increases from baseline $\mathrm{Hb}$ by $\geq 2 \mathrm{~g} / \mathrm{dL}$ not related to transfusion) was reported for $8 \%, 22 \%$, and $34 \%$ of patients in the $0.7,1.4$, and $2.1 \mu \mathrm{g} / \mathrm{kg}$ QW groups, respectively, and in $12 \%, 24 \%$, and $26 \%$ of patients in the 2.1 , 4.2 , and $6.3 \mu \mathrm{g} / \mathrm{kg} \mathrm{Q} 3 \mathrm{~W}$ groups, respectively. The proportion of patients achieving a hematopoietic response $(\mathrm{Hb}$ response or $\mathrm{Hb} \geq 12 \mathrm{~g} / \mathrm{dL}$ during the study) increased with increasing C.E.R.A. dose in both groups; $31 \%, 43 \%$, and $63 \%$ of patients in the $0.7,1.4$, and $2.1 \mu \mathrm{g} / \mathrm{kg}$ QW groups, respectively, and $35 \%, 51 \%$, and $62 \%$ of patients in the $2.1,4.2$, and $6.3 \mu \mathrm{g} / \mathrm{kg}$ Q3W groups, respectively.

The majority of patients did not require blood transfusion during the study: $64 \%, 68 \%$, and $60 \%$ of patients in the $0.7,1.4$, and $2.1 \mu \mathrm{g} / \mathrm{kg}$ QW groups, respectively, and $62 \%$, $81 \%$, and $85 \%$ of patients in the $2.1,4.2$, and $6.3 \mu \mathrm{g} / \mathrm{kg}$ 
Table 2: Summary of patients' baseline characteristics (median values, except where indicated): safety population.

\begin{tabular}{|c|c|c|c|c|c|c|}
\hline & \multicolumn{3}{|c|}{ C.E.R.A. dose group ( $\mu \mathrm{g} / \mathrm{kg}$ QW) } & \multicolumn{3}{|c|}{ C.E.R.A. dose group ( $\mu$ g/kg Q3W) } \\
\hline & 0.7 & 1.4 & 2.1 & 2.1 & 4.2 & 6.3 \\
\hline Number of patients randomized & 36 & 37 & 36 & 37 & 37 & 35 \\
\hline \multicolumn{7}{|l|}{ Sex, n, (\%) } \\
\hline Male & $23(64)$ & $22(59)$ & $26(72)$ & $22(59)$ & $20(54)$ & $28(80)$ \\
\hline Female & $13(36)$ & $15(4 I)$ & $10(28)$ & $15(4 I)$ & $17(46)$ & $7(20)$ \\
\hline Age, y (range) & $66(52-80)$ & $65(4 \mid-83)$ & $66(50-83)$ & $63(4|-9|)$ & $63(24-84)$ & $64(33-8 I)$ \\
\hline Body weight, kg (range) & $7 \mid(4 I-127)$ & $70(39-102)$ & $7 \mid(4|-9|)$ & $66(36-90)$ & $66(39-89)$ & $72(47-100)$ \\
\hline \multicolumn{7}{|l|}{ Disease stage, $n,(\%)$} \\
\hline IIIB & $9(25)$ & $10(27)$ & $9(26)$ & $13(38)$ & II (30) & $4(12)$ \\
\hline IV & $27(75)$ & $27(73)$ & $26(74)$ & $21(62)$ & $26(70)$ & $30(88)$ \\
\hline \multicolumn{7}{|c|}{ Previous treatment before study entry, $\mathrm{n},(\%)$} \\
\hline Chemotherapy & $32(89)$ & $35(95)$ & $30(86)$ & $33(97)$ & $34(92)$ & 31 (9I) \\
\hline Surgery & $13(36)$ & $10(27)$ & $7(20)$ & $8(24)$ & $11(30)$ & $9(26)$ \\
\hline Radiotherapy & $10(28)$ & $10(27)$ & $6(17)$ & $8(24)$ & $14(38)$ & $10(29)$ \\
\hline ESA & 0 & $2(5)$ & I (3) & 0 & I (3) & $2(6)$ \\
\hline Hb level, g/dL (range) & $10.2(7.1-13.9)$ & $10.2(8.1-12.8)$ & $10.3(3.5-12.7)$ & $10.4(6.8-13.3)$ & $10.1(8.0-12.9)$ & $10.6(8.0-14.0)$ \\
\hline Serum ferritin level, $\mathrm{ng} / \mathrm{mL}$ (range) & $350(55-2188)$ & $439(48-123 \mid)$ & $285(65-1403)$ & $502(92-1718)$ & $472(90-1225)$ & $507(79-1561)$ \\
\hline
\end{tabular}

C.E.R.A.: Continuous Erythropoietin Receptor Activator.

ESA: erythropoiesis-stimulating agent.

$\mathrm{Hb}$ : hemoglobin.

QW: once weekly.

Q3W: once every 3 weeks.

Q3W groups, respectively, remained transfusion-free (Figure 2). In the $6.3 \mu \mathrm{g} / \mathrm{kg} \mathrm{Q} 3 \mathrm{~W}$ group, no patient received more than one blood transfusion.

For the responder categorization analysis carried out on the Q3W group, a dose-dependent effect was seen in the proportion of 'early responders' and 'non-responders' (Figure 3). The proportion of 'additional responders' was similar in the 2.1 and $4.2 \mu \mathrm{g} / \mathrm{kg}$ groups and lowest in the $6.3 \mu \mathrm{g} / \mathrm{kg}$ group. The magnitude of mean $\mathrm{Hb}$ increase during weeks 5-13 (or last assessment) was higher in patients with an 'early response' than in those who had 'no response' regardless of the C.E.R.A. dose (-0.2 versus -1.1 $\mathrm{g} / \mathrm{dL}$ in the $2.1 \mu \mathrm{g} / \mathrm{kg}$ group; 2.4 versus $-1.5 \mathrm{~g} / \mathrm{dL}$ in the 4.2 $\mu \mathrm{g} / \mathrm{kg}$ group; 1.7 versus $-1.2 \mathrm{~g} / \mathrm{dL}$ in the $6.3 \mu \mathrm{g} / \mathrm{kg}$ group). However, these differences should be viewed with cau-

Table 3: Average hemoglobin changes from baseline during weeks 5-13 (or last assessment): intent-to-treat population.

\begin{tabular}{llc}
\hline C.E.R.A. dose group, $\mu \mathbf{g} / \mathbf{k g}$ & $\mathbf{n}$ & Least squares mean $\mathbf{( 9 5 \%} \mathbf{~ C l}) * \mathbf{H b}$ change (g/dL) \\
\hline QW & & \\
0.7 & 31 & $-0.24(-0.79$ to +0.31$)$ \\
1.4 & 35 & $0.02(-0.49$ to +0.54$)$ \\
2.1 & 34 & $0.40(-0.12$ to +0.93$)$ \\
\hline Q3W & & \\
2.1 & 31 & $-0.16(-0.75$ to +0.42$)$ \\
4.2 & 36 & $0.19(-0.35$ to +0.73$)$ \\
6.3 & 33 & $0.66(0.09$ to +1.22$)$
\end{tabular}

C.E.R.A.: Continuous Erythropoietin Receptor Activator.

$\mathrm{Hb}$ : hemoglobin.

QW: once weekly.

Q3W: once every 3 weeks.

*Derived from analysis of covariance including dose group (QW and Q3W separately) as a fixed factor and the baseline value as a covariate in the model.

$\mathrm{Cl}$ : confidence interval. 
A.

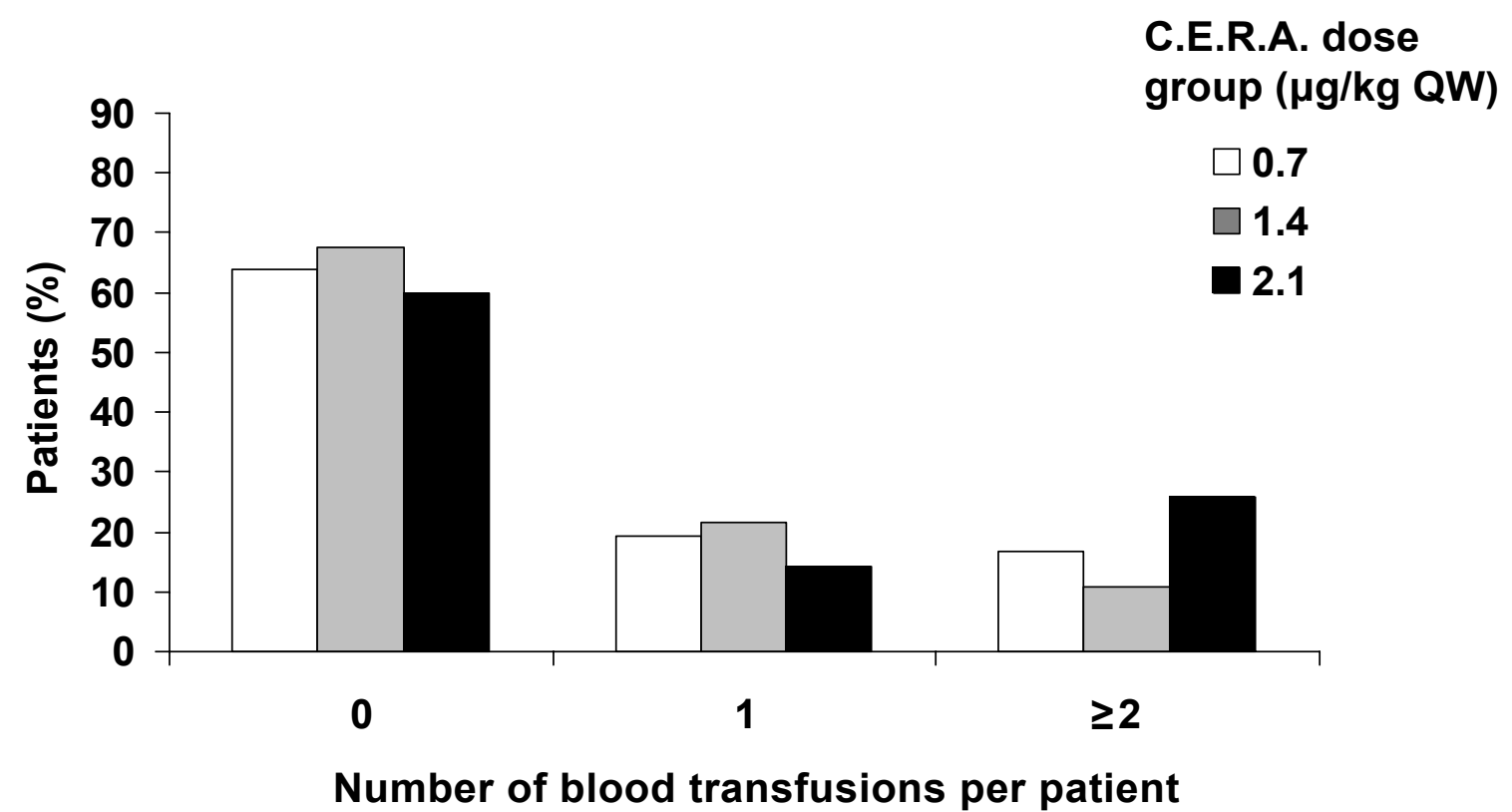

B.

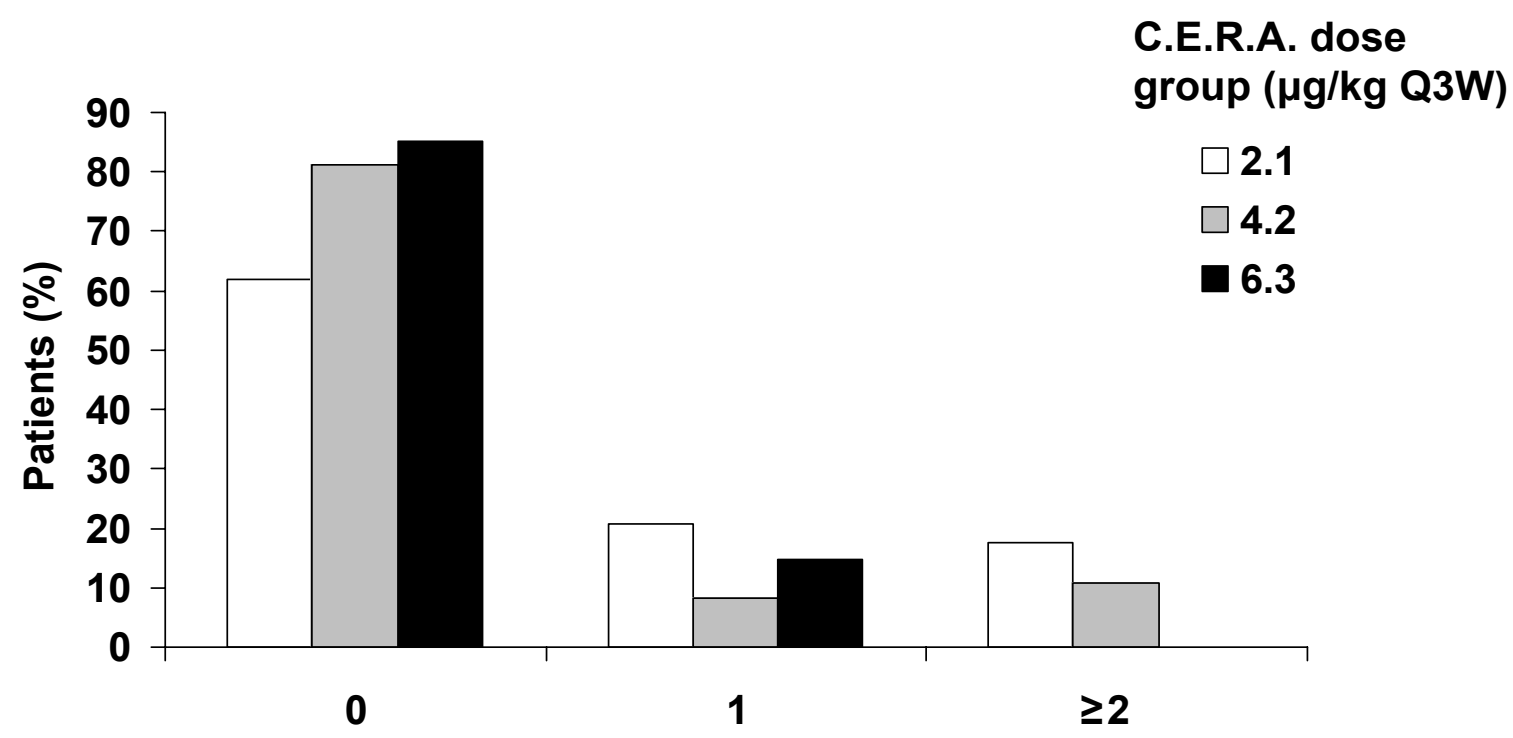

Number of blood transfusions per patient

Figure 2

Frequency of blood transfusions per patient. (A) Group administered C.E.R.A. once weekly. (B) Group administered C.E.R.A. once every 3 weeks. Intent-to-treat population.

C.E.R.A.: Continuous Erythropoietin Receptor Activator.

QW: once weekly.

Q3W: once every three weeks. 
tion, as the numbers of patients in each group were small, particularly in the $2.1 \mu \mathrm{g} / \mathrm{kg}$ group (one patient with 'early response', 14 with 'no response').

\section{Pharmacokinetics}

Pharmacokinetic parameters following SC administration of C.E.R.A. QW and Q3W are summarized in Table 4. Median $\mathrm{T}_{\max }$ values were 70-74 hours (3 days) in the QW group and 82-120 hours (3-5 days) in the Q3W group. Mean $\mathrm{C}_{\max }$ and $\mathrm{AUC}_{22-29}$ days or $\mathrm{AUC}_{22-43}$ days values increased with increasing C.E.R.A. dose in both the QW and Q3W groups. In the Q3W group, due to low clearance (median values $34.7-49.4 \mathrm{~mL} / \mathrm{h} / \mathrm{kg}$ ), mean $\mathrm{t}_{1 / 2}$ values were long, ranging from 6.5-7.8 days. The C.E.R.A. halflife could not be determined in the QW group because of low patient numbers $(\mathrm{n}=4,2,3$ in the $0.7,1.4$, and 2.1 $\mu \mathrm{g} / \mathrm{kg}$ groups, respectively). The mean C.E.R.A. serum concentrations over time in the Q3W group are shown in Figure 4.

\section{Tolerability and safety}

C.E.R.A. dose modification (dose reduced or withheld) was more frequent in the QW group compared with the Q3W group, probably because of the larger number of opportunities to change dose in the QW group. There did not appear to be a dose-related trend. In the QW group, six $(17 \%), 14(38 \%)$, and $15(43 \%)$ patients in the 0.7 , 1.4 , and $2.1 \mu \mathrm{g} / \mathrm{kg}$ groups, respectively, had C.E.R.A. dose modifications. In the Q3W group, five (15\%), $11(30 \%)$, and nine $(27 \%)$ patients in the $2.1,4.2$, and $6.3 \mu \mathrm{g} / \mathrm{kg}$ groups, respectively, had dose modifications.

C.E.R.A. doses of $0.7,1.4$, or $2.1 \mu \mathrm{g} / \mathrm{kg}$ given $\mathrm{QW}$ and 2.1, 4.2 , or $6.3 \mu \mathrm{g} / \mathrm{kg}$ given Q3W were generally well tolerated. The QW and Q3W groups showed similar tolerability pro-

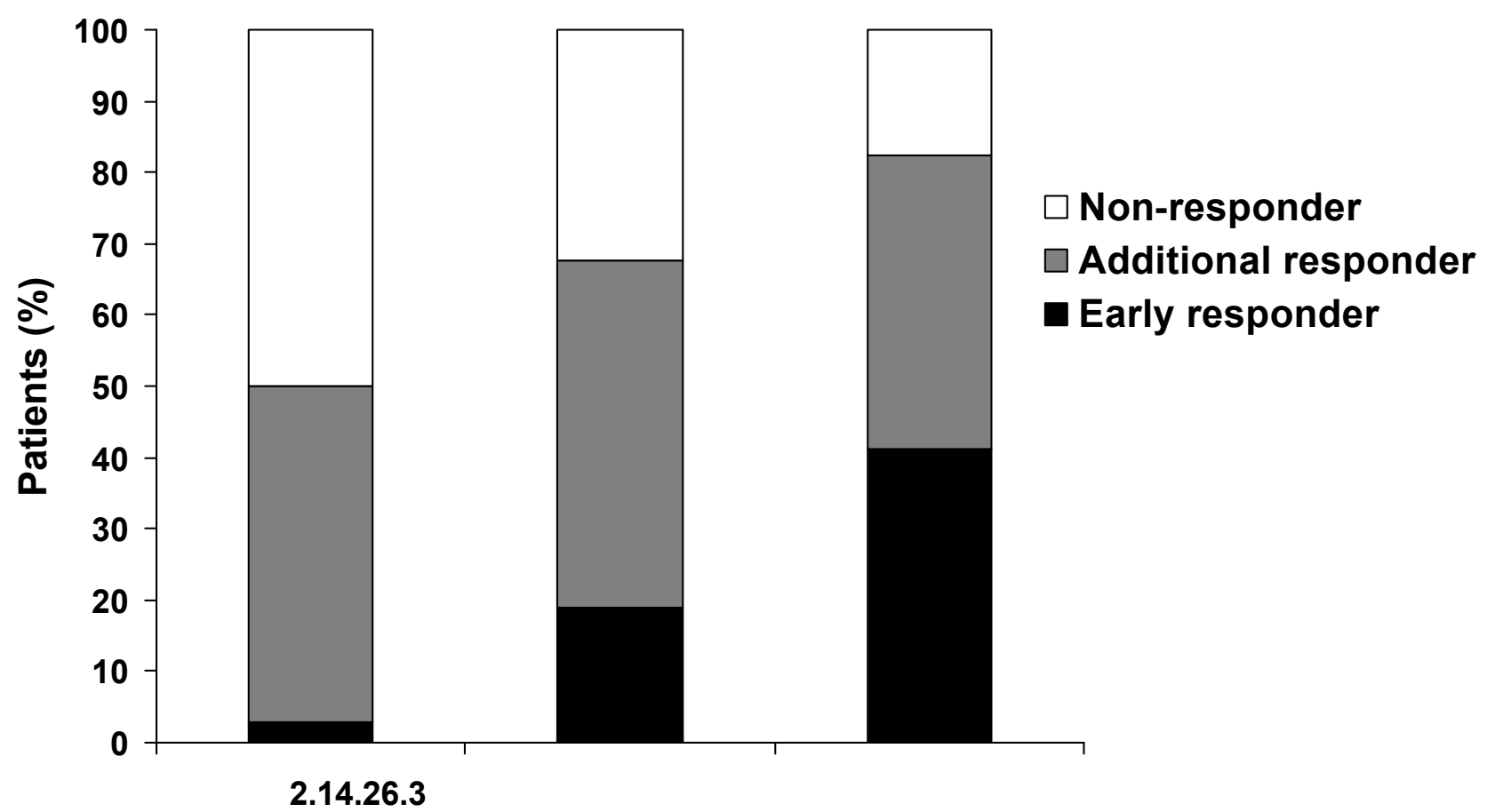

Dose of C.E.R.A. ( $\mu \mathrm{g} / \mathrm{kg} \mathrm{Q3W})$

Figure 3

Proportions of early, additional, and non-responders in group administered C.E.R.A. once every 3 weeks. Intent-to-treat population. 'Early responders': patients with $\mathrm{a} \geq \mathrm{I} \mathrm{g} / \mathrm{dL}$ increase in hemoglobin $(\mathrm{Hb})$ from baseline during the first 22 days, with no concomitant blood transfusion during the study.

'Additional responders': patients who were not early responders but achieved the target therapeutic range of $\mathrm{II}-\mathrm{I} 3 \mathrm{~g} / \mathrm{dL}$ during the study without blood transfusion.

'Non-responders': patients who did not qualify as early responders or additional responders.

C.E.R.A.: Continuous Erythropoietin Receptor Activator.

Q3W: once every three weeks. 
Table 4: Pharmacokinetic values for C.E.R.A. after subcutaneous injection. Results are given as mean \pm SD, apart from $T_{\text {max }}$ and CL/F, which are given as median values.

\begin{tabular}{|c|c|c|c|c|c|}
\hline C.E.R.A. dose group, $\mu \mathrm{g} / \mathrm{kg}$ (n) & $C_{\max }(n g / m L)$ & $T_{\max }(h)$ & AUC $(\mathrm{ng} \cdot \mathrm{h} / \mathrm{mL})^{*}$ & $t_{1 / 2}(h)$ & CL/F (mL/h/kg) \\
\hline \multicolumn{6}{|l|}{ QW } \\
\hline $0.7(14)$ & $6.7 \pm 2.5$ & 71 & $931 \pm 358$ & $17 \mid \pm 69 \dagger$ & 25.3 \\
\hline $1.4(16)$ & $10.6 \pm 4.1$ & 74 & $1355 \pm 548 \ddagger$ & $\mathrm{NC} * *$ & 25.1 \\
\hline $2.1(15)$ & $20.2 \pm 8.7$ & 70 & $2709 \pm 1193$ & $212 \pm 200^{\dagger}$ & 23.4 \\
\hline \multicolumn{6}{|l|}{ Q3W } \\
\hline $2.1(18)$ & $8.2 \pm 3.8$ & 120 & $2750 \pm 1318$ & $157 \pm 38 \dagger$ & 34.7 \\
\hline $4.2(18)$ & $16.6 \pm 9.5$ & 82 & $4651 \pm 2569 \ddagger$ & $174 \pm 44 \dagger$ & 42.8 \\
\hline $6.3(17)$ & $20.9 \pm 12.5$ & 120 & $6547 \pm 3957 \ddagger$ & $186 \pm 78 \dagger$ & 49.4 \\
\hline
\end{tabular}

AUC: area under the serum concentration-time curve.

C.E.R.A.: Continuous Erythropoietin Receptor Activator.

CL: clearance.

$\mathrm{C}_{\max }:$ maximum serum concentration.

F: bioavailability.

QW: once weekly.

Q3W: once every 3 weeks.

SD: standard deviation.

$T_{\max }$ : time to $C_{\max }$.

$\mathrm{t}_{1 / 2}$ : terminal half-life.

*AUC $22-29$ days for $\mathrm{QW}$ group and $\mathrm{AUC}_{22-43 \text { days }}$ for $\mathrm{Q} 3 \mathrm{~W}$ group.

**NC, not calculated $(\mathrm{n}=2)$.

$t_{n}=4$ and 3 in 0.7 and 2.1 QW groups, respectively, and $n=11,15,14$ in 2.1, 4.2, and 6.3 Q3W groups, respectively.

$\neq_{\mathrm{n}}=15,16$, and 14 for I.4 QW. 4.2 Q3W, and 6.3 Q3W groups, respectively.

files (Table 5). The proportion of patients reporting adverse events was similar across all treatment groups. Events were reported by $89 \%, 97 \%$, and $94 \%$ in the 0.7 , 1.4 , and $2.1 \mu \mathrm{g} / \mathrm{kg}$ QW groups, respectively, and in $94 \%$, $95 \%$, and $97 \%$ of patients in the $2.1,4.2$, and $6.3 \mu \mathrm{g} / \mathrm{kg}$ Q3W groups, respectively. The most frequently reported adverse events were nausea, fatigue, anorexia, vomiting, and neutropenia (Table 5), and were most likely secondary to chemotherapy. There did not appear to be a doserelated trend in the incidence of events.

There were 13 and 14 deaths in the QW and Q3W dose groups, respectively, none of which was considered by the investigator to be related to the study medication. Six and four patients in the QW (5.6\%) and Q3W dose group $(3.8 \%)$, respectively, had adverse events that were considered by the investigator to be related to study treatment. In the $0.7 \mu \mathrm{g} / \mathrm{kg} \mathrm{QW}$ group, one patient had four adverse events considered related to treatment (back pain, anemia, neutropenia, and hypersensitivity), one patient experienced injection site pain, one patient had pyrexia, and one patient had bone pain. In the 1.4 and $2.1 \mu \mathrm{g} / \mathrm{kg}$ QW groups, one patient in each group had thrombophlebitis. In the $2.1 \mu \mathrm{g} / \mathrm{kg} \mathrm{Q} 3 \mathrm{~W}$ group, one patient had injection site discomfort; in the $4.2 \mu \mathrm{g} / \mathrm{kg}$ Q3W group, one patient experienced flushing, hypertension, and headache, and another patient had bruising at the injection site; in the $6.3 \mu \mathrm{g} / \mathrm{kg} \mathrm{Q} 3 \mathrm{~W}$ group, one patient was reported with atrial fibrillation. Of these patients, only the patient with atrial fibrillation withdrew from the study due to the adverse event. The patient was hospitalized and treated with digoxin $0.25 \mathrm{mg}$. Normal sinus rhythm was restored soon after admission, although second degree atrioventricular heart block was recorded. Four other adverse events led to premature withdrawal from the study in the Q3W dose group (two in the $2.1 \mu \mathrm{g} / \mathrm{kg}$ group and two in the $6.3 \mu \mathrm{g} / \mathrm{kg}$ group). The reasons for withdrawal were brain metastasis (one patient) and NSCLC progression (three patients). In the QW group, eight adverse events led to premature withdrawal (three in the $0.7 \mu \mathrm{g} / \mathrm{kg}$ group, three in the $1.4 \mu \mathrm{g} / \mathrm{kg}$ group, and two in the $2.1 \mu \mathrm{g} / \mathrm{kg}$ group). The reasons for withdrawal were NSCLC progression (five patients), renal failure (one patient), worsening of anemia (one patient), and hemoptysis (one patient).

Three patients in the QW group (2.8\%; two in the $1.4 \mu \mathrm{g} /$ $\mathrm{kg}$ group and one in the $2.1 \mu \mathrm{g} / \mathrm{kg}$ group) and two patients in the Q3W group (1.9\%; both in the $4.2 \mu \mathrm{g} / \mathrm{kg}$ group) had thrombovascular events (TVEs), including thrombotic events. In the Q3W group, myocardial infarction was reported in one patient and cerebrovascular accident in another. None of the TVEs were considered by the investigator to be related to treatment with C.E.R.A. No TVEs were reported in the $6.3 \mu \mathrm{g} / \mathrm{kg}$ Q3W group.

There were no clinically significant changes from baseline in laboratory values and vital signs during the study in all dose groups, or dose-dependent relationships for increasing blood pressure. In addition, no anti-C.E.R.A. antibodies were detected. 


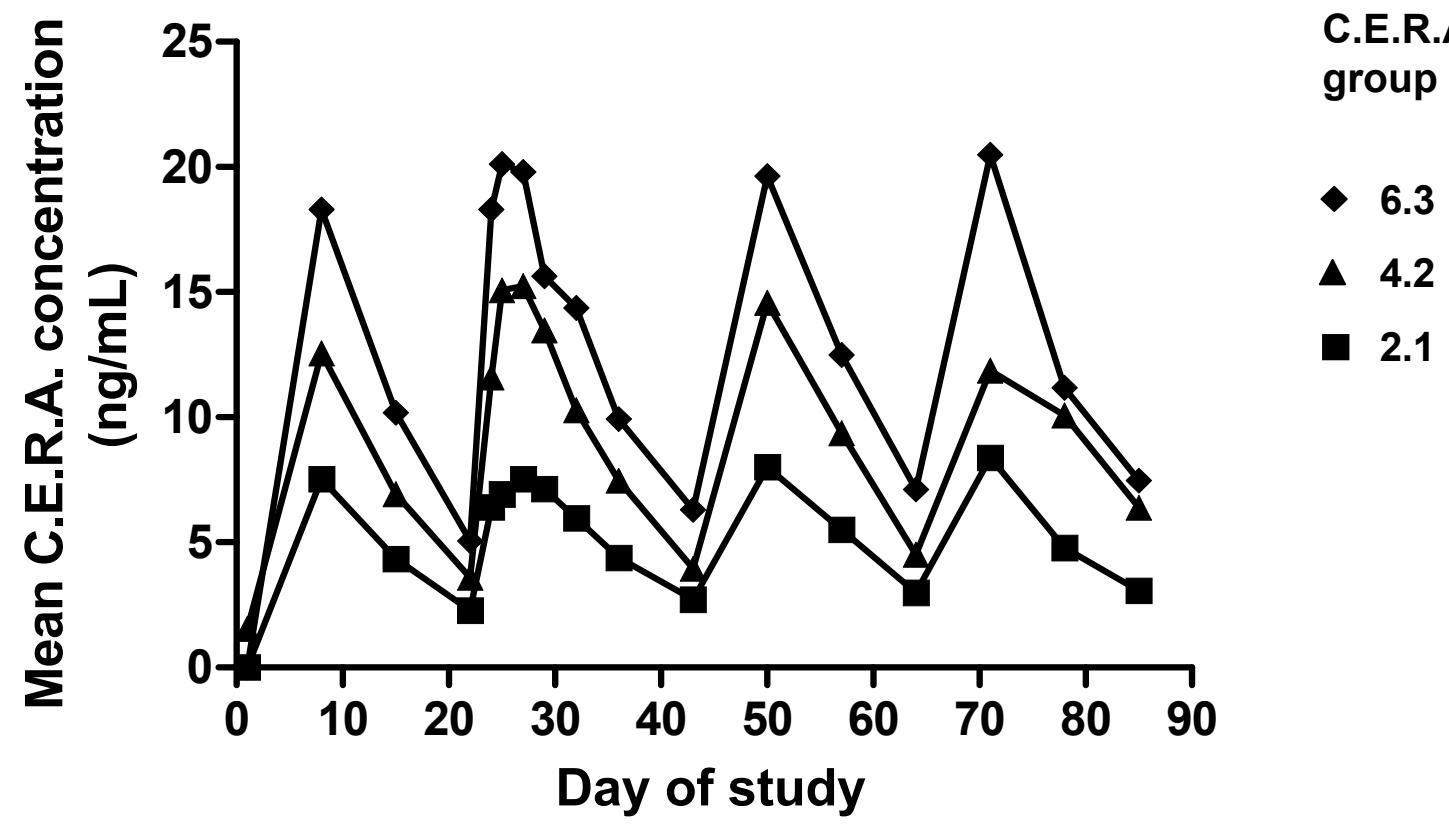

Figure 4

Mean serum concentration-time profiles for C.E.R.A. after subcutaneous injection once every 3 weeks. C.E.R.A.: Continuous Erythropoietin Receptor Activator.

Q3W: once every three weeks.

\section{Discussion}

Treatment with ESAs is now the standard of care for chemotherapy-induced anemia, resulting in increased Hb levels, reduced transfusion requirements, and improved QoL [18-22]. However, new treatments that allow less frequent administration and coordination of administration with chemotherapy regimens, and with improved early and sustained $\mathrm{Hb}$ response, would further improve the clinical profile of ESAs. C.E.R.A. is the first continuous erythropoi- etin receptor activator developed for the control of anemia in patients with cancer. In preclinical studies and healthy volunteers, C.E.R.A. was shown to have a prolonged serum half-life, suggesting that it may be administered at extended intervals when compared with ESAs $[28,29]$. A small study in patients with multiple myeloma demonstrated dose-dependent increases in maximum C.E.R.A. serum concentration and $\mathrm{Hb}$ levels over a 6-week treatment period using Q3W administration and doses up

Table 5: Most frequently reported adverse events (in $\geq 5 \%$ of patients in any treatment group). Patients administered C.E.R.A. QW or Q3W.

\begin{tabular}{|c|c|c|c|c|c|c|}
\hline \multirow[b]{2}{*}{ Adverse event, $\mathrm{n}(\%)$} & \multicolumn{3}{|c|}{ C.E.R.A. dose group ( $\mu$ g/kg QW) } & \multicolumn{3}{|c|}{ C.E.R.A. dose group ( $\mu \mathrm{g} / \mathrm{kg}$ Q3W) } \\
\hline & $0.7(n=36)$ & $1.4(n=37)$ & $2.1(n=35)$ & $2.1(n=34)$ & $4.2(n=37)$ & $6.3(n=34)$ \\
\hline Nausea & $12(33)$ & $6(16)$ & II (3I) & $11(32)$ & $7(19)$ & $4(12)$ \\
\hline Fatigue & II (3I) & $8(22)$ & $7(20)$ & $6(18)$ & $10(27)$ & $7(21)$ \\
\hline Anorexia & 7 (19) & 7 (19) & $7(20)$ & $6(18)$ & $7(19)$ & $6(18)$ \\
\hline Vomiting & $8(22)$ & $7(19)$ & $9(26)$ & $6(18)$ & $2(5)$ & $6(18)$ \\
\hline Neutropenia & $9(25)$ & $3(8)$ & $6(17)$ & $8(24)$ & 7 (19) & $4(12)$ \\
\hline Asthenia & $5(14)$ & $5(14)$ & $5(14)$ & $6(18)$ & $5(14)$ & $4(12)$ \\
\hline Cough & $8(22)$ & $3(8)$ & $3(9)$ & $5(15)$ & $4(\mathrm{II})$ & $4(12)$ \\
\hline Diarrhea & $6(17)$ & $5(14)$ & 4 (II) & $3(9)$ & $6(16)$ & $3(9)$ \\
\hline
\end{tabular}

C.E.R.A.: Continuous Erythropoietin Receptor Activator.

QW: once weekly.

Q3W: once every 3 weeks. 
to $8 \mu \mathrm{g} / \mathrm{kg}$ [27]. In addition, the proportion of patients with a $\mathrm{Hb}$ response in patients treated with C.E.R.A. 3.5$8.0 \mu \mathrm{g} / \mathrm{kg}(50.0 \%-62.5 \%)$ compared favorably with values obtained in studies of epoetin beta and darbepoetin alfa given QW in cancer patients receiving myelosuppressive chemotherapy $[19,31]$. The present study examined the efficacy, safety, and pharmacokinetic profile of C.E.R.A. in anemic patients with Stage IIIB or IV NSCLC receiving myelosuppressive chemotherapy. The dose range chosen was based on the doses shown to be effective in the multiple myeloma study [27]. In this study, patients with NSCLC receiving chemotherapy were administered one of six doses of C.E.R.A. (0.7-2.1 $\mu \mathrm{g} / \mathrm{kg}$ QW or 2.1-6.3 $\mu \mathrm{g} / \mathrm{kg} \mathrm{Q} 3 \mathrm{~W})$ by SC injection.

The results demonstrated that C.E.R.A. treatment led to dose-related improvements in patients' anemia. Increases in mean $\mathrm{Hb}$ level and $\mathrm{Hb}$ response were observed with increasing doses of C.E.R.A. administered Q3W and QW. Dose-dependent increases in $\mathrm{Hb}$ were also observed when the change from baseline during week 5 to week 13 was assessed; but it is important to achieve more substantial erythropoietic benefits, which could be observed with higher doses of C.E.R.A. It is also interesting to note that, although the study was not powered to compare dose schedules, there was an inclination for higher increases in mean $\mathrm{Hb}$ level overall and during week 5 to week 13 when the same dose over time was given Q3W rather than QW.

The majority of patients in the 4.2 and $6.3 \mu \mathrm{g} / \mathrm{kg}$ Q3W groups (51\% and $62 \%$, respectively) and $2.1 \mu \mathrm{g} / \mathrm{kg}$ QW group $(63 \%)$ achieved a hematopoietic response. In addition, in the Q3W group, the proportion of 'early responder' patients increased with increasing C.E.R.A. dose, reaching $41 \%$ with the highest dose. Adding together the proportions of 'early responders' and 'additional responders', the total response in the $6.3 \mu \mathrm{g} / \mathrm{kg}$ group was $82 \%$. Conversely, the proportion of patients who did not respond to C.E.R.A. treatment decreased with increasing C.E.R.A. dose. There was also an indication that early response was predictive of later $\mathrm{Hb}$ increases. The magnitude of mean $\mathrm{Hb}$ increase during weeks 5-13 was higher in 'early responders' than in patients who did not show early response.

The majority of patients in all six treatment groups did not require blood transfusion during the study. There was a trend for a greater transfusion-saving effect with C.E.R.A. administered Q3W compared with QW treatment; 60\% of patients in the $2.1 \mu \mathrm{g} / \mathrm{kg}$ QW group did not require transfusion in comparison with $85 \%$ of patients administered the same weekly dose Q3W (6.3 $\mu \mathrm{g} / \mathrm{kg} \mathrm{Q} 3 \mathrm{~W})$. Also, in the $6.3 \mu \mathrm{g} / \mathrm{kg} \mathrm{Q} 3 \mathrm{~W}$ group, of the $15 \%$ of patients that required blood transfusion, all received only one transfusion during the study. This suggests a positive drug effect, as previous studies suggested a very high rate (up to 59\%) of transfusion use in patients with lung cancer receiving platinum therapy without the support of an ESA [32,33].

The major limitations of the current study design included the lack of a placebo or active control group in the study, the limited range of C.E.R.A. doses, and the lack of dose increase in the event of an inadequate $\mathrm{Hb}$ response. Most other studies of ESAs in patients with lung cancer allowed dose increases in patients who did not respond [20,3436]. Despite this, the $\mathrm{Hb}$ and hematopoietic response rates from this study compare well with those from studies of ESA treatment of anemia in patients with lung cancer receiving chemotherapy. In a study of darbepoetin alfa QW treatment, the proportion of patients with a hematopoietic response (defined as an increase in $\mathrm{Hb}$ of $\geq 2.0 \mathrm{~g} /$ $\mathrm{dL}$ or $\mathrm{Hb} \geq 12 \mathrm{~g} / \mathrm{dL}$ in the absence of transfusion in the previous 28 days) was $66 \%$ [20]. This response rate was similar to the $62 \%$ hematopoietic response rate achieved in the C.E.R.A. $6.3 \mu \mathrm{g} / \mathrm{kg}$ Q3W group in the present study. However, a more stringent definition of response was applied in the current study (confirmed on two consecutive measurements in this study versus a single measurement in the darbepoetin alfa study). Also, nearly half of patients (43\%) in the darbepoetin alfa study required dose doubling to $4.5 \mu \mathrm{g} / \mathrm{kg}$ QW because of inadequate response to $2.25 \mu \mathrm{g} / \mathrm{kg} \mathrm{QW}[20,37]$. Therefore, it is reasonable to hypothesize that response rates in the present study could have been even higher if dose increases had been permitted.

Despite the presence of some similarities with other studies, one has to be careful when comparing the results of the present study with those of some previous trials of ESA treatment in lung cancer. Most previous ESA studies included a mixture of patients with small cell lung cancer and NSCLC [20,34-36,38-40] in contrast to this study which included only Stage IIIB or IV NSCLC patients. Other factors compromising between-study comparisons include differences in patient populations in terms of disease stages and chemotherapy intensity. In terms of disease stage, a study of darbepoetin alfa $200 \mu \mathrm{g}$ every 2 weeks and epoetin alfa 40,000 IU QW examined the hematopoietic response in patients with breast, gynecologic, or Stage IIIB/IV NSCLC [36]. The mean change from baseline $\mathrm{Hb}$ at the end of treatment (up to 16 weeks) was lowest in patients with advanced NSCLC: 0.6 and $1.3 \mathrm{~g} / \mathrm{dL}$ in the darbepoetin alfa and epoetin alfa groups, respectively, in comparison with increases of 1.7-1.9 g/dL or 1.3 $\mathrm{g} / \mathrm{dL}$ in patients with breast cancer or gynecologic cancer. The late disease stage was thought to have contributed to the poorer responses in the NSCLC patients [36]. Also, the intensity of chemotherapy varied in previous studies of patients with Stage III/IV NSCLC [20,35,36,39]. In the present study, most patients had received chemotherapy 
before the study and all received chemotherapy during the study, most commonly platinum based (65\% to $91 \%$ ). The use of platinum compounds has been shown to have a negative impact on $\mathrm{Hb}$ levels in patients with lung cancer [5].

The pharmacokinetic profile of C.E.R.A., including a prolonged half-life and low clearance, is different to that of epoetin alfa and darbepoetin alfa [26]. The half-life of C.E.R.A. was considerably longer than that of the ESAs. Epoetin alfa has a half-life of approximately 40-44 hours in cancer patients $[41,42]$ and approximately 19 hours in healthy volunteers [43]. Darbepoetin alfa has a half-life of 39-74 hours in cancer patients [44,45] and 49 hours in patients with kidney disease [46]. The $t_{1 / 2}$ (mean 157-186 hours) of C.E.R.A. reported in this study was similar to the values observed in patients with multiple myeloma [27], healthy volunteers [29], and renal patients [47].

C.E.R.A. administered Q3W and QW with concomitant chemotherapy was generally well tolerated across all dose groups. The adverse events reported were mainly related to the effects of chemotherapy or the underlying disease. The incidences of fatigue, anorexia, and dyspnea were similar to those reported in the darbepoetin alfa trial of lung cancer patients [20], whereas the incidence of nausea, most likely related to chemotherapy, appeared to be lower in the C.E.R.A. study (12\%-33\% versus approximately $42 \%$ ). On the other hand, in a retrospective analysis of three epoetin alfa lung cancer studies, the incidence of adverse events was lower than in the C.E.R.A. study [34]. These different findings may be explained by dose non-comparability and methodological differences between the separate studies, making direct comparisons difficult. TVEs were reported by three patients in the QW group (two in the $1.4 \mu \mathrm{g} / \mathrm{kg}$ dose group and one in the 2.1 $\mu \mathrm{g} / \mathrm{kg}$ dose group) and two patients in the Q3W group (4.2 $\mu \mathrm{g} / \mathrm{kg}$ dose group). There were no TVEs in the $6.3 \mu \mathrm{g} /$ $\mathrm{kg}$ dose Q3W group. All TVEs were considered to be unrelated to C.E.R.A. by the investigator. This TVE incidence is similar to that reported with placebo treatment in metaanalyses of ESA studies [48,49].

\section{Conclusion}

The $\mathrm{Hb}$ results in this study show that C.E.R.A. administered SC QW or Q3W has clinical activity in patients with Stage IIIB (pleural effusion) or IV NSCLC. There were dose-dependent and sustained increases in response related to $\mathrm{Hb}$ level with increasing C.E.R.A. dose levels on QW and Q3W dosing schedules. The proportion of patients with early responses also increased with increasing C.E.R.A. dose administered Q3W, reaching $41 \%$ in the $6.3 \mu \mathrm{g} / \mathrm{kg}$ group. There was an inclination for improved effectiveness of C.E.R.A. in terms of mean $\mathrm{Hb}$ level increases and transfusion use when the same dose over time was given Q3W as opposed to QW. In the $6.3 \mu \mathrm{g} / \mathrm{kg}$ Q3W group, most patients remained transfusion-free $(85 \%)$ during the study, with no patients in the $6.3 \mu \mathrm{g} / \mathrm{kg}$ group requiring more than one transfusion. C.E.R.A. was generally well tolerated across all dose groups. These results suggest that C.E.R.A. Q3W has the potential to reduce the burden of anemia management for patients and healthcare providers by providing an effective alternative to transfusions in a treatment that can be synchronized with a patient's chemotherapy regimen.

Confirmation of the previously defined pharmacokinetic profile of C.E.R.A., and its good tolerability and safety profile in this study of patients with advanced NSCLC, also suggest that extended administration intervals are feasible in the clinic. However, further dose-finding studies that use higher doses and allow dose escalation are required to determine the optimal C.E.R.A. Q3W dose regimen in anemic cancer patients receiving chemotherapy. The results of other studies with C.E.R.A. in the treatment of chemotherapy-related anemia are awaited.

\section{Competing interests}

$\mathrm{VH}, \mathrm{JG}, \mathrm{CM}, \mathrm{PM}$ and RR have received honoraria from Hoffmann-La Roche. JEE is an employee of Hoffmann-La Roche Inc. and possesses shares in Hoffmann-La Roche.

\section{Authors' contributions}

$\mathrm{VH}$ was Principle Investigator for the study described in the manuscript. VH, JG, PM, CM, and RR participated in designing and performing the research. JEE participated in the analysis and interpretation of data. All authors participated in drafting and revising the manuscript and all authors read and approved the final manuscript.

\section{Acknowledgements}

This study was funded by Hoffmann-La Roche Inc., Nutley, NJ. Medical writing support was provided by Joanne Knowles at Prime Medica during the preparation of this paper, supported by Roche. Responsibility for opinions, conclusions, and interpretation of data lies with the authors.

In addition to the authors of the present paper, the following investigators participated in the study: Mark Adler (USA), Bipinkumar Amin (USA), Juan Carlos Alcedo (Panama), Donald Berdeaux (USA), Leon Bosquee (Belgium), Linda Bosserman (USA), Peter Briggs (Australia), German Calderillo (Mexico), Felipe Cardenal Alemany (Spain), Michael Clemens (Germany),

Antonio Contu (Italy), Christopher Croot (USA), Sheldon Davidson (USA), Peter Eisenberg (USA), Enriqueta Felip (Spain), Nashat Gabrail (USA), Ulrich Gatzemeier (Germany), Ahmad Gill (USA), Glenwood Goss (Canada), Teresa Hayes (USA), David Henry (USA), James Ho (China), Agnieszka Jagiello-Gruszfeld (Poland), Erzsebet Juhasz (Hungary), Eckhard Kaukel (Germany), Dusan Kotasek (Australia), Maciej Krzakowski (Poland), Han Pin Kuo (Taiwan), Francis Laberge (Canada), Christopher Lee (Canada), Richard Lloyd (USA), Roberto Sergio Lugo Quintana (Mexico), Barbara Melosky (Canada), Skaidrius Miliauskas (Lithuania), Tony Shu Kam Mok (China), Harold Olney (Canada), Amalio Ordonez (Spain), Richard Orlowski (USA), Gyula Ostoros (Hungary), Kishan Pandya (USA), Warren Paroly (USA), Ravi Patel (USA), Ettore Piroso (USA), Riccardo Rosso 
(Italy), Bruce Saidman (USA), Lucia Santome (Spain), Lee Schwartzberg (USA), Sigitas Stonkus (Lithuania), Aleksandra Szczesna (Poland), Barna Szima (Hungary), Julie Taguchi (USA), Simon Tchekmedyian (USA), Ilona Vinkler (Hungary), Joachim Von Pawel (Germany), Deepika Wali (USA), Chih-Hsin James Yang (Taiwan), Lorrin Yee (USA)

\section{References}

I. Jemal A, Murray T, Ward E, Samuels A, Tiwari RC, Ghafoor A, Feuer EJ, Thun MJ: Cancer statistics, 2005. CA Cancer J Clin 2005, 55(I): $10-30$

2. Groopman JE, Itri LM: Chemotherapy-induced anemia in adults: incidence and treatment. I Natl Cancer Inst 1999, 91(19): I616-1634.

3. Kelly K, Crowley J, Bunn PA Jr, Presant CA, Grevstad PK, Moinpour CM, Ramsey SD, Wozniak AJ, Weiss GR, Moore DF, Israel VK, Livingston RB, Gandara DR: Randomized phase III trial of paclitaxel plus carboplatin versus vinorelbine plus cisplatin in the treatment of patients with advanced non-small-cell lung cancer: a Southwest Oncology Group trial. I Clin Oncol 2001, I9(13):3210-3218.

4. Sweeney CJ, Zhu J, Sandler AB, Schiller J, Belani CP, Langer C, Krook J, Harrington D, Johnson DH: Outcome of patients with a performance status of 2 in Eastern Cooperative Oncology Group Study E 1594: a Phase II trial in patients with metastatic nonsmall cell lung carcinoma. Cancer 200I, 92(10):2639-2647.

5. Kosmidis P, Krzakowski M, The ECAS Investigators: Anemia profiles in patients with lung cancer: what have we learned from the European Cancer Anaemia Survey (ECAS)? Lung Cancer 2005, 50(3):40I-4I2.

6. Crawford J: Anemia and lung cancer. Lung Cancer 2002 38(Suppl 3):S75-S78

7. Langer C], Choy H, Glaspy JA, Colowick A: Standards of care for anemia management in oncology: focus on lung carcinoma. Cancer 2002, 95(3):613-623.

8. Nowrousian MR, Kasper C, Oberhoff C, Essers U, Voigtmann R, Gallasch W, Quarder O: Pathophysiology of cancer-related anemia. In rhErythropoietin in Cancer Supportive Treatment Edited by Smyth JF, Boogaerts MA, Ehmer BR-M. New York: Marcel Dekker, Inc; 1996:13-34.

9. Faquin WC, Schneider TJ, Goldberg MA: Effect of inflammatory cytokines on hypoxia-induced erythropoietin production. Blood 1992, 79(8): 1987-1994.

10. Cella D: Factors influencing quality of life in cancer patients: anemia and fatigue. Semin Oncol 1998, 25(3 Suppl 7):43-46.

II. Pirker R, Wiesenberger K, Pohl G, Minar W: Anemia in lung cancer: clinical impact and management. Clin Lung Cancer 2003, 5(2):90-97.

12. Morère JF: Role of epoetin in the management of anaemia in patients with lung cancer. Lung Cancer 2004, 46(2): | 49-1 56.

13. Albain KS, Crowley J], LeBlanc M, Livingston RB: Survival determinants in extensive-stage non-small-cell lung cancer: the Southwest Oncology Group experience. J Clin Oncol 1991, 9(9): 1618-1626.

14. MacRae R, Shyr $Y$, Johnson D, Choy H: Declining hemoglobin during chemoradiotherapy for locally advanced non-small cell lung cancer is significant. Radiother Oncol 2002, 64(I):37-40.

15. Robnett TJ, Machtay M, Hahn SM, Shrager JB, Friedberg JS, Kaiser LR: Pathological response to preoperative chemoradiation worsens with anemia in non-small cell lung cancer patients. Cancer J 2002, 8(3):263-267.

16. Barrett-Lee PJ, Bailey NP, O'Brien ME, Wager E: Large scale UK audit of blood transfusion requirements and anaemia in patients receiving cytotoxic chemotherapy. Br J Cancer 2000, 82(I):93-97

17. Goodnough LT, Brecher ME, Kanter MH, AuBuchon JP: Transfusion medicine. First of two parts - blood transfusion. N Engl J Med 1999, 340(6):438-447.

18. Littlewood T], Bajetta E, Nortier JW, Vercammen E, Rapoport B, Epoetin Alfa Study Group: Effects of epoetin alfa on hematologic parameters and quality of life in cancer patients receiving nonplatinum chemotherapy: results of a randomized, double-blind, placebo-controlled trial. J Clin Oncol 200I, I 9( I I ):2865-2874.
19. Österborg A, Brandberg Y, Molostova V, losava G, Abdulkadyrov K, Hedenus M, Messinger D: Randomized, double-blind, placebocontrolled trial of recombinant human erythropoietin, epoetin beta, in hematologic malignancies. J Clin Oncol 2002 20( I 0):2486-2494.

20. Vansteenkiste J, Pirker R, Massuti B, Barata F, Font A, Fiegl M, Siena S, Gateley J, Tomita D, Colowick AB, Musil J, Aranesp 980297 Study Group: Double-blind, placebo-controlled, randomized phase III trial of darbepoetin alfa in lung cancer patients receiving chemotherapy. I Natl Cancer Inst 2002, 94( I 6): I 2 | I- I 220.

21. Boogaerts M, Coiffier B, Kainz C, Epoetin $\beta$ QOL Working Group: Impact of epoetin $\beta$ on quality of life in patients with malignant disease. Br J Cancer 2003, 88(7):988-995

22. Wilkinson PM, Antonopoulos M, Lahousen M, Lind M, Kosmidis $\mathrm{P}$ EPO-INT-45 Study Group: Epoetin alfa in platinum-treated ovarian cancer patients: results of a multinational, multicentre, randomised trial. $\mathrm{Br} J$ Cancer 2006, 94(7):947-954.

23. Cazzola M, Beguin Y, Kloczko J, Spicka I, Coiffier B: Once-weekly epoetin beta is highly effective in treating anaemic patients with lymphoproliferative malignancy and defective endogenous erythropoietin production. $\mathrm{Br} J$ Haematol 2003, I 22(3):386-393.

24. Waltzman $R$, Croot $C$, Justice GR, Fesen MR, Charu V, Williams D Randomized comparison of epoetin alfa (40,000 $U$ weekly) and darbepoetin alfa (200 microg every 2 weeks) in anemic patients with cancer receiving chemotherapy. Oncologist 2005 , I 0(8):642-650.

25. Macdougall IC, Bailon P, Tare T, Pahlke W: CERA (Continuous Erythropoiesis Receptor Activator) for the treatment of renal anemia: an innovative agent with unique receptor binding characteristics and prolonged serum half-life. I Am Soc Nephrol 2003, I 4:769A. (Abstract SU-POI063)

26. Macdougall IC: CERA (Continuous Erythropoietin Receptor Activator): a new erythropoiesis-stimulating agent for the treatment of anemia. Curr Hematol Rep 2005, 4(6):436-440.

27. Dmoszynska A, Klockzo J, Rokicka M, Hellmann A, Spicka I: Efficacy and pharmacokinetics of CERA (Continuous Erythropoiesis Receptor Activator) in patients with multiple myeloma: an exploratory Phase I-II dose escalation study. Proc Am Soc Clin Oncol 2004, 23:568. (Abstract 6552)

28. Haselbeck A, Reigner B, Jordan P, Pannier A, Glaspy J: Pre-clinical and Phase I pharmacokinetic and mode-of-action studies of CERA (Continuous Erythropoiesis Receptor Activator), an innovative erythropoietic agent with an extended serum half-life. Proc Am Soc Clin Oncol 2003, 22:748. (Abstract 3006)

29. Dougherty FC, Reigner B, Jordan P, Pannier A: Continuous Erythropoiesis Receptor Activator (CERA) provides dose-dependent erythropoietic activity with a prolonged half-life in healthy volunteers. Ann Oncol 2004, I 5(Suppl 3):iii I57. (Abstract 592)

30. Reigner B, Jordan P, Pannier A, Glaspy J: CERA (Continuous Erythropoiesis Receptor Activator), an innovative agent: dose-dependent response in Phase I studies. Proc Am Soc Clin Oncol 2003, 22:732. (Abstract 2943)

31. Hedenus M, Adriansson M, San Miguel J, Kramer MH, Schipperus MR, Juvonen E, Taylor K, Belch A, Altes A, Martinelli G, Watson D, Matcham J, Rossi G, Littlewood TJ, Darbepoetin Alfa 20000I6I Study Group: Efficacy and safety of darbepoetin alfa in anaemic patients with lymphoproliferative malignancies: a randomized, double-blind, placebo-controlled study. $\mathrm{Br} J$ Haematol 2003, I 22(3):394-403.

32. Henry DH, Brooks BJ Jr, Case DC Jr, Fishkin E, Jacobson R, Keller AM, Kugler J, Moore J, Silver RT, Storniolo AM, Abels RI, Gordon DS, Nelson R, Larholt K, Bryant E, Rudnick S: Recombinant human erythropoietin therapy for anemic cancer patients receiving cisplatin chemotherapy. Cancer J Sci Am I995, I (4):252-260.

33. Thatcher N, De Campos ES, Bell DR, Steward WP, Varghese G, Morant R, Vansteenkiste JF, Rosso R, Ewers SB, Sundal E, Schatzmann $E$, Stocker $H$ : Epoetin alpha prevents anaemia and reduces transfusion requirements in patients undergoing primarily platinum-based chemotherapy for small cell lung cancer. $\mathrm{Br}$ J Cancer 1999, 80(3-4):396-402.

34. Crawford J, Demetri GD, Gabrilove JL, Blasi MV, Sarokhan BJ, Glaspy $\mathrm{J}$ : Clinical benefits of epoetin alfa therapy in patients with lung cancer. Clin Lung Cancer 2002, 3(3): 180-190. 
35. Casas F, Vinolas N, Ferrer F, Farrus B, Gimferrer JM, Agusti C, Belda J, Luburich P: Improvement in performance status after erythropoietin treatment in lung cancer patients undergoing concurrent chemoradiotherapy. Int J Radiat Oncol Biol Phys 2003, 55(I): I16-124.

36. Schwartzberg LS, Yee LK, Senecal FM, Charu V, Tomita D, Wallace J, Rossi G: A randomized comparison of every-2-week darbepoetin alfa and weekly epoetin alfa for the treatment of chemotherapy-induced anemia in patients with breast, lung, or gynecologic cancer. Oncologist 2004, 9(6):696-707.

37. Coiffier $B$ : Epoetin once weekly in anaemic patients with cancer. Br J Haematol 2004, I 25(I): I00-I0I.

38. Hardut D, Wiesenberger K, Minar W, Pirker R: Epoetin beta in patients with lung cancer receiving chemotherapy. Lung Cancer 2003, 4I (Suppl 2):S264. (Abstract AP-682I)

39. Ariganello O, Mancuso A, Di Molfetta M, Diana F, Beccaglia P, Cortesi $E$, De Marinis F: A new induction schedule of epoetin alfa 40.000 IU in anemic patients with advanced lung cancer. Lung Cancer 2004, 46(I): I I9-124.

40. Pirker R, Lehnert M, Minar W: Epoetin beta 30,000 IU once weekly for the treatment of anaemia in patients with lung cancer receiving chemotherapy: a prospective survey of the efficacy and timing of treatment in a clinical setting. Lung Cancer 2005, 49(Suppl 2):S340. (Abstract P-840)

4I. Cheung WK, Danneman B, Wacholtz M, Lau H, Miller D: Pharmacokinetics (PK) and pharmacodynamics (PD) of epoetin alfa in anemic cancer patients receiving cycling chemotherapy. Blood 2004, 104(II):(Abstract 4I0I).

42. Procrit $^{\circledR}$ (epoetin alfa) package insert. Edited by: Raritan NJ. Ortho Biotech Products, LP; 2004.

43. Halstenson CE, Macres M, Katz SA, Schnieders JR, Watanabe M, Sobota JT, Abraham PA: Comparative pharmacokinetics and pharmacodynamics of epoetin alfa and epoetin beta. Clin Pharmacol Ther 199|, 50(6):702-7|2.

44. Glaspy J, Henry D, Patel R, Tchekmedyian S, Applebaum S, Berdeaux D, Lloyd R, Berg R, Austin M, Rossi G, Darbepoetin Alfa 20010162 Study Group: Effects of chemotherapy on endogenous erythropoietin levels and the pharmacokinetics and erythropoietic response of darbepoetin alfa: a randomized clinical trial of synchronous versus asynchronous dosing of darbepoetin alfa. Eur J Cancer 2005, 4 I (8): I I 40-I I 49.

45. Heatherington AC, Dittrich C, Sullivan JT, Rossi G, Schueller J: Pharmacokinetics of darbepoetin alfa after intravenous or subcutaneous administration in patients with non-myeloid malignancies undergoing chemotherapy. Clin Pharmacokinet 2006, 45(2): |99-2II.

46. Macdougall IC, Gray SJ, Elston O, Breen C, Jenkins B, Browne J, Egrie $\mathrm{J}$ : Pharmacokinetics of novel erythropoiesis stimulating protein compared with epoetin alfa in dialysis patients. J Am Soc Nephrol I999, I ( (I I):2392-2395.

47. Macdougall IC, Robson R, Opatrna S, Liogier X, Pannier A, Reigner B, Dougherty FC: Pharmacologic profile of CERA (Continuous Erythropoietin Receptor Activator) in chronic kidney disease (CKD) patients (pts) following intravenous (IV) and subcutaneous (SC) administration. J Am Soc Nephrol 2005, 16:759A. (Abstract SA-PO926)

48. Bohlius J, Langensiepen S, Schwarzer G, Seidenfeld J, Piper M, Bennett $C$, Engert A: Recombinant human erythropoietin and overall survival in cancer patients: results of a comprehensive metaanalysis. J Natl Cancer Inst 2005, 97( I6):489-498.

49. Coiffier B, Boogaerts M, Aapro M, Huber M, Burger H-U: Thromboembolic events in patients with cancer treated with epoetin beta: a meta-analysis of controlled clinical trials. Ann Oncol 2004, 3:iii221. (Abstract 840P)
Publish with Biomed Central and every scientist can read your work free of charge

"BioMed Central will be the most significant development for disseminating the results of biomedical research in our lifetime. "

Sir Paul Nurse, Cancer Research UK

Your research papers will be:

- available free of charge to the entire biomedical community

- peer reviewed and published immediately upon acceptance

- cited in PubMed and archived on PubMed Central

- yours - you keep the copyright

Submit your manuscript here:

http://www.biomedcentral.com/info/publishing_adv.asp
BiolMedcentral 